\title{
A simple model of snow albedo decay using observations from the Community Collaborative Rain, Hail, and Snow-Albedo (CoCoRaHS-Albedo) Network
}

\author{
TRISTAN AMARAL, ${ }^{1,2}$ CAMERON P. WAKE, ${ }^{1,3}$ JACK E. DIBB, ${ }^{1,3}$ \\ ELIZABETH A. BURAKOWSKI, ${ }^{1,3}$ MARY STAMPONE ${ }^{4}$ \\ ${ }^{1}$ Department of Earth Sciences, University of New Hampshire, Durham, New Hampshire, USA \\ ${ }^{2}$ Now at Department of Geological Sciences, University of Idaho, Moscow, USA \\ ${ }^{3}$ Earth Systems Research Center, Institute for the Study of Earth, Oceans, and Space, University of New Hampshire, USA \\ ${ }^{4}$ Department of Geography, Institute for the Study of Earth, Oceans, and Space, University of New Hampshire, USA \\ Correspondence: Cameron P. Wake <cameron.wake@unh.edu>
}

\begin{abstract}
The albedo of seasonal snow cover plays an important role in the global climate system due to its influence on Earth's radiation budget and energy balance. Volunteer Community Collaborative Rain, Hail, and Snow-Albedo (CoCoRaHS-Albedo) observers collected 3249 individual daily albedo, snow depth and density measurements using standardized techniques at dozens of sites across New Hampshire, USA over four winter seasons. The data show that albedo increases rapidly with snow depth up to $\sim 0.14 \mathrm{~m}$. Multiple linear regression models using snowpack age, snow depth or density, and air temperature provide reasonable approximations of surface snow albedo during times of albedo decay. However, the linear models also reveal systematic biases that highlight an important non-linearity in snow albedo decay. Modeled albedo values are reasonably accurate within the range of 0.6-0.9, but exhibit a tendency to overestimate lower albedo values and underestimate higher albedo values. We hypothesize that rapid reduction in high albedo fresh snow results from a decrease in snow specific surface area, while during melt-events the presence of liquid water in the snowpack accelerates metamorphism and grain growth. We conclude that the CoCoRaHS-Albedo volunteer observer network provides useful snow albedo, depth and density measurements and serves as an effective model for future measurement campaigns.
\end{abstract}

KEYWORDS: snow, snow metamorphosis, snow/ice surface processes

\section{INTRODUCTION}

Surface albedo is an important component of the global climate system due to its influence on Earth's radiation budget and energy balance. The snow-albedo feedback modifies climate through its impact on surface air temperatures and snow cover extent, and exerts a particularly strong influence in polar regions and regions of seasonal snow (Groisman and others, 1994; Pedersen and Winther, 2005; Mote, 2008; Flanner and others, 2011; Fletcher and others, 2012). Recent trends of decreasing days with snow cover across the Northeast United States (Burakowski and others, 2008) and diminishing snow cover extent over the entire northern hemisphere during spring months (Lemke and others, 2007; Brown and Robinson, 2011; Estilow and others, 2015) are observed in synchrony with increasing wintertime and springtime air temperatures.

Quantifying the change of snow albedo on daily, seasonal and interannual timescales is critical for improving our understanding of the temporal variability in the surface energy balance and surface temperature (Burakowski and others, 2016). In mid-latitude regions, snow cover follows a seasonal cycle as well as exhibiting interannual variability (Robock, 1980). New snowfall events and snowpack evolution processes drive fluctuations in snow albedo on timescales of days, initiating changes in the amount of radiation absorbed by the surface (Warren and Wiscombe, 1980; Flanner and Zender, 2006). While the mechanisms controlling the increase in albedo following a fresh snowfall event are relatively straightforward, small-scale snowpack metamorphic processes that drive day-to-day albedo decay are more complicated and challenging to model accurately (Qu and Hall, 2006).

Although theoretical relationships between snowpack evolution and albedo decay are well established (Warren and Wiscombe, 1980; Wiscombe and Warren, 1980; Warren, 1982; Flanner and Zender, 2006), direct surface observations of snow albedo remain sparse or inconsistent, especially in areas of seasonal snow cover (van den Broeke and others, 2004; Gardner and Sharp, 2010). Here, we report on daily snow depth, density and surface albedo measurements collected across the state of New Hampshire by the Community Collaborative Rain, Hail and Snow-Albedo (CoCoRaHSAlbedo) volunteer science network (Burakowski and others, 2013). The Community Collaborative Rain, Hail and Snow (CoCoRaHS) Network was established in 1998 in response to a 1997 flash flood in Fort Collins, Colorado, USA (Cifelli and others, 2005). The network consists of over 7000 citizen scientist volunteers who collect daily rain, hail and/or snow observations using low-cost instrumentation in all 50 US states. CoCoRaHS data are used in a variety of research applications 
including weather forecasting (Schwartz, 2014), drought monitoring (DeGaetano and others, 2015), satellite verification (Sharma and others, 2013; Sugg and others, 2014) and model validation (Hopper and Schumacher, 2012; Smith and others, 2015). In 2011, the CoCoRaHS-Albedo pilot project was launched to recruit CoCoRaHS observers to also collect daily snow albedo measurements (Burakowski and others, 2013).

Among the sub-arctic research stations that measure albedo, most lack associated snow density and depth measurements (Table 1). The Surface Albedo Validation Sites (SAVS 1.0; Loew and others, 2016) provides a one-stop clearinghouse for many of the sites in Table 1. However, it focuses on categorizing albedo sites by spatial and topographical heterogeneity and does not provide associated snow depth or density measurements. Within the Cryonet network, only five of the 32 sites are in sub-arctic regions and not situated on glaciers. There remains a dearth of in-situ albedo observations from spatially-distributed sites that can be used to investigate the factors controlling albedo changes in mid-latitude seasonal snowpacks. Here, the spatially and temporally dense observations from CoCoRaHS-Albedo measurements in New Hampshire over four winter seasons provide a unique opportunity to examine how albedo evolves with changing snowpack properties across an array of sites. The data we present are used to develop and test an empirical model to estimate albedo decay across the Northeast United States over periods of days via a suite of simple, readily available snowpack and atmospheric parameters.

\section{METHODS}

Volunteer observers collected daily albedo, snow depth and snow density measurements across New Hampshire for four winter seasons (December 2011-April 2015; Table 2) using custom-designed snow sampling and albedo kits (Burakowski and others, 2013). Concurrently, daily snow albedo, depth and density measurements were collected by University of New Hampshire (UNH) scientists at a site in Durham, New Hampshire. Due to a variety of reasons, the records from volunteer sites contain missing days. The ground surface at observation sites were mainly mowed lawns (lawn/athletic field) with the exceptions of sites NH-GR-11 (wooden observation deck), NH-MR-06, (bare soil) and NH-ST-99 (hay field mowed for harvest in late summer). Site elevations ranged from 20 to $545 \mathrm{~m}$ a.s.l. and proximity to the Atlantic Ocean coastline ranged from 7 to $147 \mathrm{~km}$ (Table 3). The spatial distribution of observation sites provides reasonable statewide coverage (Fig. 1).

The CoCoRaHS-Albedo kits were designed to be simple to use, yet capable of collecting scientifically useful data. An individual kit consists of a 2 -foot $(0.61 \mathrm{~m})$ and a 4 -foot $(1.22 \mathrm{~m})$ aluminum snow tube with internal diameter of $46 \mathrm{~mm}$, a metal scraper, a hanging digital scale (CCi Model HS-6, CCi Scale Company, Clovis, CA), an Apogee MP-200 pyranometer (Apogee Instruments, Logan, UT) mounted onto a $0.91 \mathrm{~m}$ aluminum boom with circular bubble-levels and a field notebook. Each observer received a 1- to 2-hour training session by project personnel on how to correctly measure albedo, snow depth, snow density, maintain equipment and enter data online.

Snow depth (SD) measurements were obtained by vertically inserting the snow tube into the snowpack and recording depth to the nearest half inch $(13 \mathrm{~mm})$ according to the scale on the tube's side (field measurements use US customary units in alignment with national CoCoRaHS protocol). The tube bottom opening at the ground/snow interface was covered with the metal scraper before the tube was removed from the snowpack, and the bottom of the tube capped. The tube, cap and snow were weighed. The tare weight of the empty capped snow tube was subtracted from the total weight to yield the mass $(M)$ of snow contained inside, which was then used to calculate snow density. Estimates of snow density include the following uncertainties: $\mathrm{SD} \pm 0.13 \mathrm{~mm}$ for the snow depth measurement (half from measurement scale on snow tube and half from potentially uneven ground surface); $M \pm 0.2 \mathrm{~g}$ for the mass measurement; and a minimal error associated with the radius $(r)$ of the tube, estimated at $r \pm 0.0 .5 \mathrm{~mm}$.

Albedo is defined as the ratio of upwelling $\left(S W_{u p}\right)$ to downwelling $\left(S W_{\text {down }}\right)$ solar radiation:

$$
\alpha=\frac{\mathrm{SW}_{u p}}{\mathrm{SW}_{\text {down }}}
$$

Downwelling radiation was measured by positioning the Apogee MP-200 optic upwards in a horizontal manner; upwelling, or reflected radiation, was measured by inverting the optic to measure reflected radiation. The levels attached to both sides of the aluminum boom were used to ensure that the pyranometer was level for every measurement. Daily albedo values were calculated as the sum of three upwelling measurements divided by the sum of three downwelling paired radiation measurements using Eqn (1). Snow albedo

Table 1. Inventory of research stations that collect in situ field measurements of snow albedo, density and depth ( $\mathrm{Y}=$ yes, $N=$ no)

\begin{tabular}{|c|c|c|c|c|c|}
\hline Network & Citation & No. of sites & Albedo & Snow density & Snow depth \\
\hline GC-Net, Greenland & Steffen and others (1996) & 18 & Y & $\mathrm{N}$ & $\mathrm{N}$ \\
\hline SURFRAD, USA & Augustine and others (2000) & 7 & Y & $\mathrm{N}$ & $\mathrm{N}$ \\
\hline Ameriflux, Americas & Ameriflux.lbl.gov & 197 & Y & $\mathrm{N}$ & $\mathrm{N}$ \\
\hline BSRN, global & Bsrn.awi.de & 12 & Y & $\mathrm{N}$ & $\mathrm{N}$ \\
\hline Cryonet, global & Various* & 32 & Y & $\mathrm{Y}$ & $\mathrm{Y}$ \\
\hline PROMICE, Greenland & van As and others (2013) & 25 & $\mathrm{Y}$ & $\mathrm{N}$ & $\mathrm{N}$ \\
\hline Alaska \& Colorado & Malik and others (2014) & 6 & Y & $\mathrm{N}$ & $\mathrm{Y}$ \\
\hline Global soil moisture data bank & Robock and others (2000) & 6 & $\mathrm{Y}$ & $\mathrm{N}$ & $\mathrm{N}$ \\
\hline BOREAS, Canada & Shewchuk (1997) & 10 & $\mathrm{Y}$ & $\mathrm{N}$ & $\mathrm{Y}$ \\
\hline Svalbard & Pedersen and Winther (2005) & 1 & Y & $\mathrm{N}$ & \\
\hline CoCoRaHS-Albedo, New Hampshire, USA & Burakowski and others (2013) & 20 & Y & $\mathrm{Y}$ & $\mathrm{Y}$ \\
\hline
\end{tabular}

\footnotetext{
* see globalcryospherewatch.org for list of sites and associated citations.
} 
Table 2. Time period and inventory of observers for snowpack measurements over four winters used in this study

\begin{tabular}{|c|c|c|c|c|c|c|}
\hline Winter number & Start & End & Citizen observers & School observers & Total observers & $\begin{array}{l}\text { Albedo decay intervals } \\
\text { lasting } \geq 4 \text { days }\end{array}$ \\
\hline W1 & December 2011 & April 2012 & 17 & 0 & 17 & 12 \\
\hline W2 & November 2012 & April 2013 & 11 & 7 & 18 & 32 \\
\hline W3 & December 2013 & April 2014 & 10 & 9 & 19 & 30 \\
\hline W4 & December 2014 & April 2015 & 6 & 8 & 14 & 22 \\
\hline
\end{tabular}

is only weakly dependent on solar zenith angle $(\theta)$ when $\theta<50^{\circ}$ (Wiscombe and Warren, 1980), however since $\theta$ is $>50^{\circ}$ at the northernmost CoCoRaHS-Albedo sites during winter, albedo observations were taken within an hour of solar noon to minimize influence of solar zenith angle. Solar noon was determined for each site using the National Oceanic and Atmospheric Administration (NOAA) Solar Noon Calculator (http://www.esrl.noaa.gov/gmd/grad/ solcalc/). Estimates of percent cloud cover were also recorded when the albedo measurements were made.

Volunteer observers began collecting albedo, snow depth and snow density measurements during late November or early December, depending on the date of first snowfall. They were instructed to take several snow-free albedo readings prior to the first snowfall event to test the equipment (for use in related land-cover albedo study) and for educational purposes to clearly demonstrate the difference in reflectivity between snow-free and snow-covered surfaces. Following spring snowmelt, volunteers again took several more snowfree albedo measurements at each sampling site. Snow-free measurements were also collected during mid-winter if melt events created bare ground between snow-covered periods. Recorded field observations for each day of sampling were entered into a digital data entry form on the CoCoRaHS-Albedo website (http://www.cocorahs-albedo. org/) along with general weather observations such as cloud cover, recent snowfall amounts, days since previous snow fall and melt events.

The Apogee MP-200 instrument measures total shortwave broadband (360 nm-1120 nm) albedo with an absolute accuracy of \pm 0.05 , calibrated against a Kipp and Zonen CMA6 albedometer (Burakowski and others, 2013). A spatial variability experiment was conducted in March 2014 consisting of 16 albedo measurement sites spaced $1.5 \mathrm{~m}$ apart in a $6 \mathrm{~m} \times 6 \mathrm{~m}$ grid adjacent to the CoCoRaHS-Albedo observation site in Durham, NH. Albedo measurements were made with the Apogee MP-200 following CoCoRaHSAlbedo protocol for 5 consecutive days. Conditions were typical of early melt-season, with a snow depth of $\sim 0.25 \mathrm{~m}$, midday $2 \mathrm{~m}$ air temperatures close to $0^{\circ} \mathrm{C}$, snow density

Table 3. Summary information for all sites participating in the CoCoRAHS-Albedo network from 2011 to 2015

\begin{tabular}{|c|c|c|c|c|c|c|c|c|c|c|c|}
\hline \multirow[t]{2}{*}{ City/town ${ }^{\mathrm{a}}$} & \multirow[t]{2}{*}{ Station } & \multirow[t]{2}{*}{ Lat } & \multirow[t]{2}{*}{ Long } & \multirow{2}{*}{$\begin{array}{l}\text { Elev } \\
\text { m }\end{array}$} & \multirow[t]{2}{*}{$\mathrm{Km}$ from coast } & \multicolumn{5}{|c|}{ Number of observations } & \multirow[t]{2}{*}{ Nearest met. station } \\
\hline & & & & & & W1 & W2 & W3 & W4 & Total & \\
\hline Amherst & NH-HL-25 & 42.9 & -71.6 & 276 & 41 & 22 & 81 & 46 & 85 & 234 & USC00272302 \\
\hline Bath & NH-GR-4 & 44.2 & -72.0 & 600 & 91 & 18 & 0 & 0 & 0 & 18 & USC00270493 \\
\hline Berlin & NH-CS-14 & 44.5 & -71.2 & 1104 & 71 & 0 & 41 & 42 & 42 & 125 & USC00270690 \\
\hline Bow & NH-MR-4 & 43.2 & -71.6 & 469 & 41 & 80 & 89 & 81 & 79 & 329 & USW00014745 \\
\hline Conway & NH-CR-32 & 44.0 & -71.1 & 462 & 45 & 0 & 0 & 2 & 0 & 2 & USC00177479 \\
\hline Danbury & NH-MR-6 & 43.5 & -71.8 & 937 & 65 & 74 & 97 & 106 & 67 & 344 & USC00273182 \\
\hline Derry & NH-RC-52 & 42.9 & -71.3 & 41 & 95 & 0 & 0 & 0 & 7 & 7 & USC00273626 \\
\hline Dover & NH-ST-30 & 43.2 & -70.8 & 67 & 10 & 0 & 59 & 1 & 0 & 60 & USW00054795 \\
\hline Durham & NH-ST-99 & 43.1 & -71.0 & 66 & 13 & 34 & 90 & 106 & 92 & 322 & USW00054795 \\
\hline E.Wakefield & NH-CR-1 & 43.6 & -71.0 & 603 & 29 & 63 & 0 & 0 & 0 & 63 & USC00177479 \\
\hline Exeter & NH-RC-46 & 43.0 & -71.0 & 19 & 36 & 0 & 49 & 45 & 37 & 131 & USC00273626 \\
\hline Gilsum & $\mathrm{NH}-\mathrm{CH}-15$ & 43.1 & -72.2 & 1065 & 72 & 11 & 0 & 0 & 0 & 11 & USC00274399 \\
\hline Greenland & NH-RC-13 & 43.0 & -70.8 & 86 & 4 & 9 & 28 & 53 & 0 & 90 & USC00273626 \\
\hline Greenville & NH-HL-48 & 42.8 & -71.8 & 1013 & 49 & 24 & 0 & 0 & 0 & 24 & USC00272302 \\
\hline Hampstead & NH-RC-29 & 42.9 & -71.2 & 325 & 19 & 21 & 0 & 0 & 0 & 21 & USC00279278 \\
\hline Keene & NH-CH-19 & 42.9 & -72.3 & 124 & 155 & 0 & 0 & 0 & 46 & 46 & USC00274399 \\
\hline Keene & $\mathrm{NH}-\mathrm{CH}-4$ & 42.9 & -72.3 & 808 & 77 & 52 & 0 & 0 & 0 & 52 & USC00274399 \\
\hline Lancaster & NH-CS-7 & 44.3 & -71.6 & 1404 & 78 & 86 & 86 & 50 & 95 & 317 & USC00274556 \\
\hline Lyme & NH-GR-37 & 43.7 & -72.3 & 519 & 91 & 0 & 0 & 18 & 0 & 18 & CRREL \\
\hline Nashua & NH-HL-58 & 42.7 & -71.5 & 155 & 34 & 0 & 0 & 35 & 10 & 45 & USC00275712 \\
\hline Newbury & NH-MR-41 & 43.3 & -72.1 & 1597 & 70 & 0 & 3 & 0 & 0 & 3 & USW00014745 \\
\hline Plymouth & NH-GR-11 & 43.8 & -71.7 & 573 & 65 & 43 & 105 & 98 & 80 & 326 & KPLY \\
\hline Randolph & NH-CS-10 & 44.4 & -71.3 & 1787 & 69 & 76 & 56 & 77 & 44 & 253 & USC00270690 \\
\hline Sunapee & NH-SL-8 & 43.4 & -72.1 & 1354 & 73 & 53 & 82 & 92 & 85 & 312 & USC00275868 \\
\hline Sutton & NH-MR-11 & 43.3 & -71.9 & 912 & 62 & 39 & 79 & 99 & 0 & 217 & USC00270913 \\
\hline Whitefield & NH-CS-11 & 44.4 & -71.6 & 1021 & 83 & 3 & 0 & 0 & 0 & 3 & USW00054728 \\
\hline Windham & ME-CM-100 & 43.8 & -70.4 & 274 & 11 & 0 & 0 & 25 & 0 & 25 & USC00179720 \\
\hline
\end{tabular}

Sites in bold identify those that contributed data used in model calibration and evaluation.

a All stations except Windham, Maine (ME) are in the US state of New Hampshire (NH).

b All but the KPLY and CRREL sites are Global Historical Climatology Network stations. 


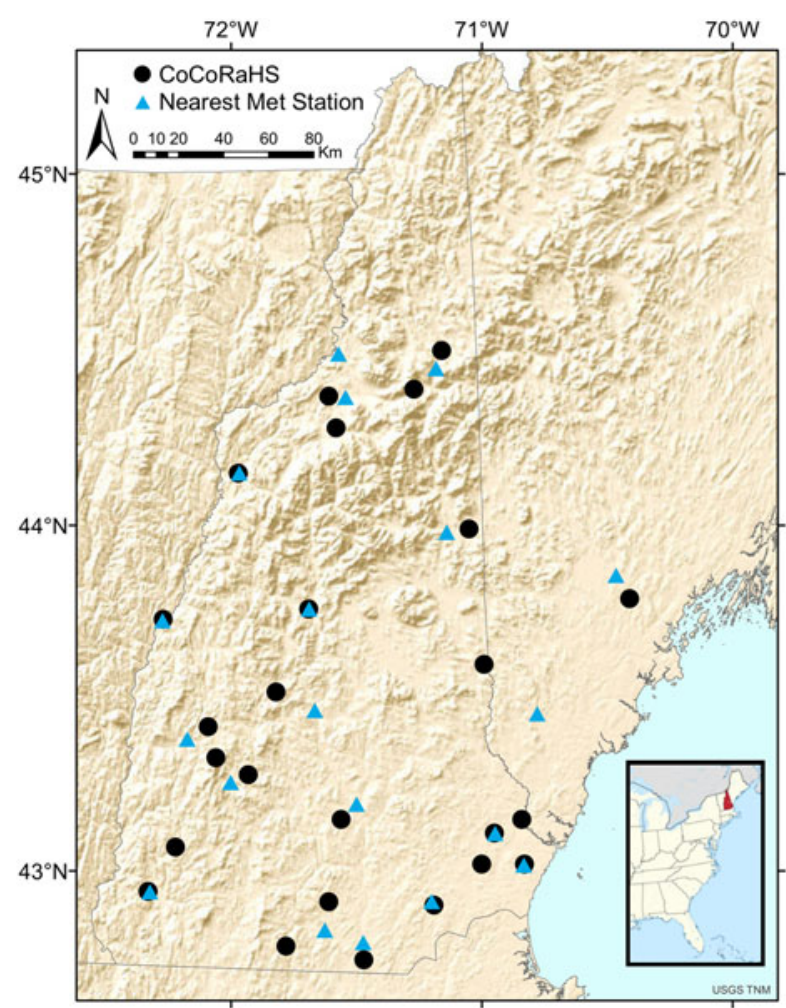

Fig. 1. Location of CoCoRAHS-Albedo measurement sites (black dots; primarily in New Hampshire, USA) and meteorological stations (blue triangles) that provided data used in this study.

near $350 \mathrm{~kg} \mathrm{~m}^{-3}$, surface albedo of $\sim 0.75$, and varying cloud cover between days. Under these circumstances, the coefficient of variation in surface albedo measurements among the 16 grid measurements ranged from 1 to $2 \%$.

Maximum, minimum and daily average $2 \mathrm{~m}$ air temperatures were obtained from weather stations located closest to the albedo measurement site. Weather stations include Global Historical Climatology Network (GHCN) stations, a municipal airport weather station (KPLY) and the Cold Regions Research and Engineering Laboratory (CRREL) automatic weather station (Table 2). Most meteorological stations were not co-located with the CoCoRaHS-Albedo observation sites, but are all within $25 \mathrm{~km}$, and 21 (of 27) are within $10 \mathrm{~km}$ (Fig. 1). Due to the relative proximity of the albedo and $2 \mathrm{~m}$ air temperature measurements, the $2 \mathrm{~m}$ air temperature records are assumed to be representative of conditions at the albedo measurement sites.

\subsection{Albedo decay model development}

To explore snow albedo decay over time, data from individual intervals of albedo decay were selected from the database of all CoCoRaHS-Albedo measurements. Decay intervals are defined by consecutive albedo decline lasting 4 or more days at a specific site, regardless of the month they occur or the starting albedo value. The threshold of 4 days represents a length of time long enough to capture fundamental processes of snowpack aging and albedo decline in our data but not so long as to severely limit the number of decay intervals available for analysis from our dataset.

We identify a total of 96 intervals of albedo decay lasting 4 or more days in length, including 12 from $\mathrm{W} 1,32$ from $\mathrm{W} 2$, 30 from W3, and 22 from W4 (Table 2). By month, 11 occurred during December, 29 during January, 14 during February, 34 during March and 8 during April. Just over half of the decay periods (49 of 96) last only 4 days in duration while the other 47 range from 5 to 16 days.

Most of the measured albedo decay intervals begin immediately after a snowfall event; however, several begin a day or two after the end of the snowfall event. This delay may be due to small errors in albedo measurement associated with the time of measurement, changes in atmospheric or surface conditions (e.g. cloud cover, snow redistribution by the wind), or occasional missed albedo measurements. Of the 96 decay intervals used in model construction and validation, 64 begin within 1 day of a fresh snowfall and 80 begin within 3 days of a recorded snowfall event. Comparison of the rate of albedo reduction over time between decay intervals, which begin promptly following a snowfall and those which begin later reveals similar patterns of albedo decay.

Multiple linear regression models were constructed to estimate surface albedo values as a function of snowpack age, snowpack properties and $2 \mathrm{~m}$ air temperature statistics. Since the number of variables involved in a linear regression represents a trade-off between adding variables to improve prediction but limiting input variable redundancy, we first calculated pairwise linear correlations between albedo and candidate snowpack properties (daily depth, density and snow water equivalent (SWE)) and $2 \mathrm{~m}$ air temperature measures (daily minimum, maximum and average). The snowpack property and $2 \mathrm{~m}$ air temperature variables with strongest correlations to albedo were then used with snowpack age in the multiple linear regression models

The 96 albedo decay intervals were divided randomly into 'calibration' and 'evaluation' datasets using the random number function rand.m in Matlab R2014b. The calibration set was used to build the multiple linear regression models. The models were then tested on the evaluation dataset. To assess whether model performance was sensitive to calibration and evaluation data selection, a sensitivity analysis was conducted in which the 96 decay intervals were randomly sorted into two equivalent datasets over 10 iterations. Model performance statistics were gathered on each random iteration and used to determine the influence of data selection on model evaluation (Table 4).

Table 4. Summary statistics for model sensitivity to calibration and evaluation dataset selection

\begin{tabular}{|c|c|c|c|c|c|c|}
\hline \multirow[t]{2}{*}{ Run } & \multicolumn{3}{|c|}{$\begin{array}{c}\text { Shallow snow regression } \\
\text { model }\end{array}$} & \multicolumn{3}{|c|}{$\begin{array}{c}\text { Deep snow regression } \\
\text { model }\end{array}$} \\
\hline & $r$ & RMSE & $m$ & $r$ & RMSE & $m$ \\
\hline 1 & 0.76 & 0.12 & 0.41 & 0.70 & 0.08 & 0.47 \\
\hline 2 & 0.69 & 0.10 & 0.56 & 0.73 & 0.07 & 0.49 \\
\hline 3 & 0.75 & 0.10 & 0.64 & 0.71 & 0.07 & 0.64 \\
\hline 4 & 0.68 & 0.10 & 0.51 & 0.73 & 0.08 & 0.40 \\
\hline 5 & 0.74 & 0.10 & 0.57 & 0.67 & 0.08 & 0.51 \\
\hline 6 & 0.75 & 0.10 & 0.51 & 0.70 & 0.08 & 0.53 \\
\hline 7 & 0.72 & 0.11 & 0.48 & 0.70 & 0.07 & 0.56 \\
\hline 8 & 0.74 & 0.10 & 0.66 & 0.71 & 0.07 & 0.52 \\
\hline 9 & 0.72 & 0.11 & 0.39 & 0.73 & 0.08 & 0.47 \\
\hline 10 & 0.70 & 0.10 & 0.57 & 0.74 & 0.08 & 0.49 \\
\hline
\end{tabular}

Multiple linear regression models constructed using calibration data were tested on evaluation data. Model performance was assessed via linear correlation coefficient $(r)$, RMSE and slope of linear fit $(m)$. 

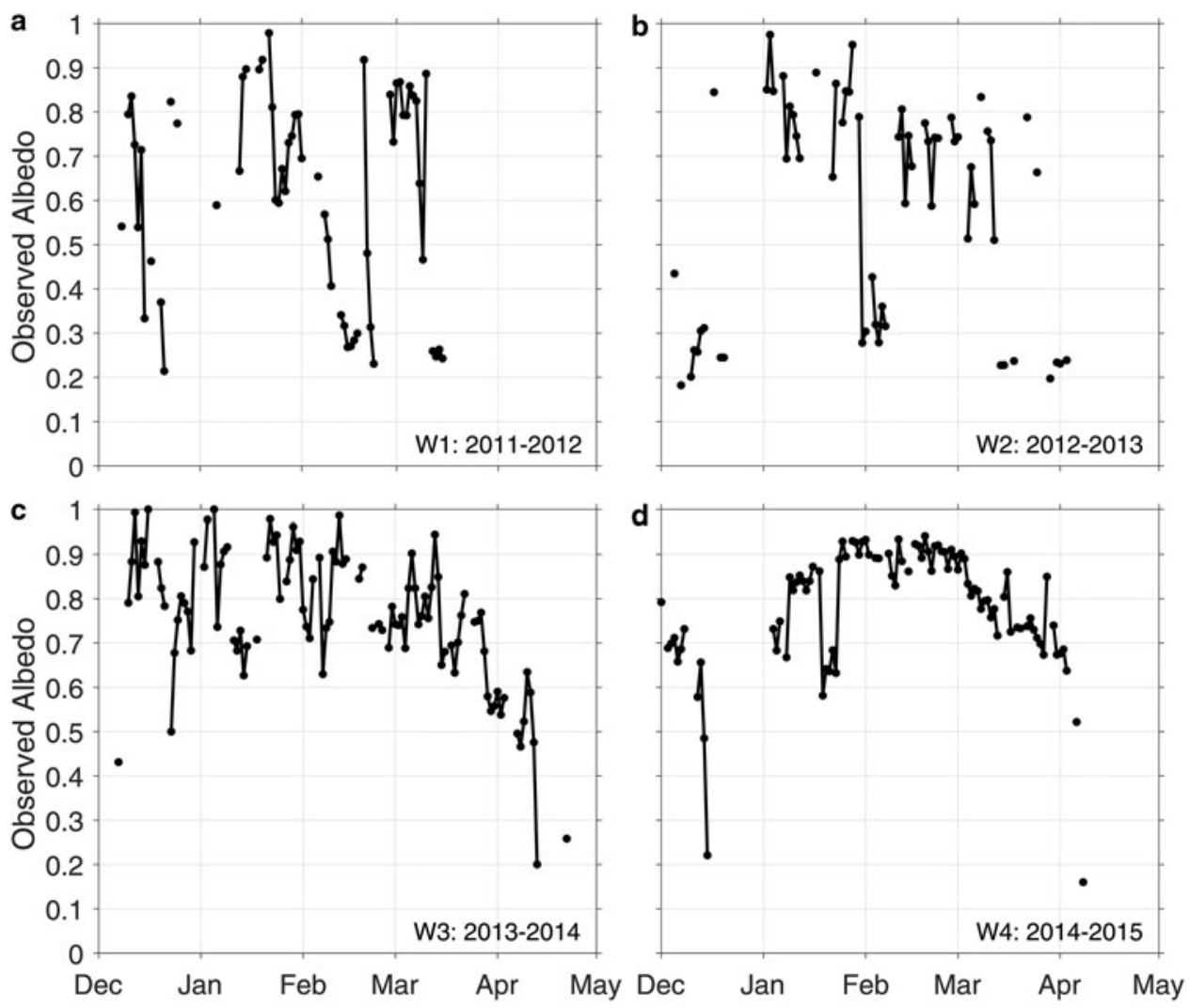

Fig. 2. Surface albedo measured in Durham, NH during (a) Winter 1 (December 2011-April 2012), (b) Winter 2 (2012/13), (c) Winter 3 (2013/ 14) and (d) Winter $4(2014 / 15)$.

\section{RESULTS}

A total of 3249 individual daily albedo and snowpack measurements were collected by volunteer observers over the course of the four winter seasons at 27 different observer sites. Measured snow albedo exhibits significant day-to-day variability; the albedo record from Durham, $\mathrm{NH}$ for all four winter seasons provides an example of this variability (Fig. 2).

The 96 decay intervals (497 total measurements) show considerable variability in the rate of surface albedo decline over time (Fig. 3). Within the first day following peak albedo, albedo reductions range from 0.01 to 0.25 . After the first 2 days, albedo values decline by 0.01 to 0.32 and after three days, albedo reductions range from 0.03 to 0.47 .

Baker and others (1991) quantify the snow depth above which the snowpack is considered to be optically thick and whereupon the underlying terrain is effectively masked. Our data show that albedo increases rapidly with snow depth up to $\sim 0.14 \mathrm{~m}$. Further deepening of the snow up to $\sim 0.50 \mathrm{~m}$ does not result in a corresponding increase in albedo (Fig. 4). A modest increase in albedo is apparent as SD increase from 0.5 to $0.8 \mathrm{~m}$. A snow depth threshold of $0.14 \mathrm{~m}$ is subsequently used to divide the 96 decay intervals into shallow (SD $<0.14 \mathrm{~m}$; 'non-optically thick') snow and deep (SD > $0.14 \mathrm{~m}$; 'optically thick') snow regimes.

Snow albedo for both shallow and deep snowpacks showed high negative correlations with snow age and daily average $2 \mathrm{~m}$ temperature (Fig. 5). Shallow snowpacks show the highest (positive) correlation with daily snow depth, while deeper snowpacks show strongest (negative) correlation with daily snow density. Surprisingly, daily SWE was not highly correlated with albedo in either shallow or deep snowpacks.

\subsection{Multiple linear regression}

Based on the results shown in Figure 5, snow age ( $\tau$ in days), average daily $2 \mathrm{~m}$ air temperature $\left(T\right.$ in $\left.{ }^{\circ} \mathrm{C}\right)$, and daily snow depth (SD in $\mathrm{m}$ ) for shallow snowpacks and daily snow density $\left(\rho\right.$ in $\mathrm{kg} \mathrm{m}^{-3}$ ) for deep snowpacks, were selected for use in our multiple linear regression analysis. Multiple linear regression models were constructed for both groups using ten randomly generated calibration and evaluation datasets (Table 4). A test of the 95\% confidence intervals for the slope of each model's goodness of fit statistics revealed no significant trends over the course of the ten

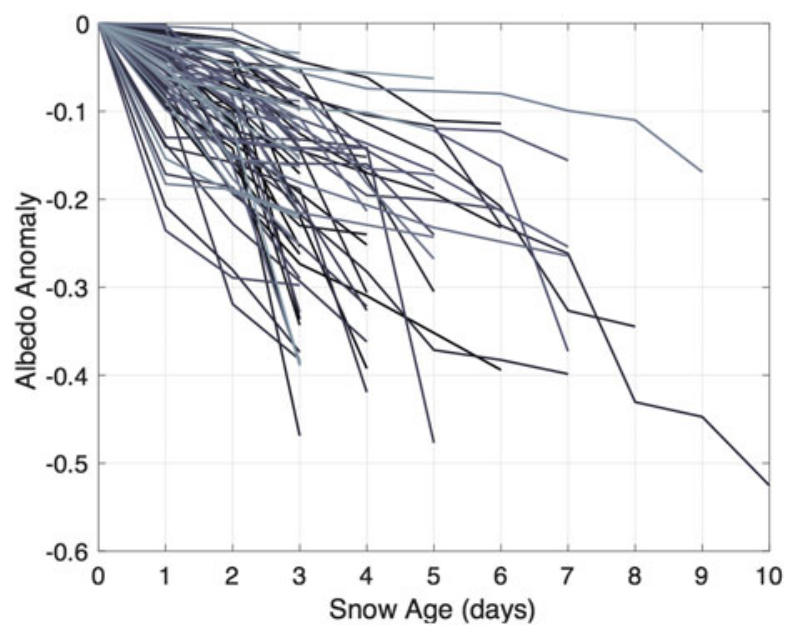

Fig. 3. Albedo decay events plotted as an albedo anomaly calculated from Day 0. Each line represents a single albedo decay event. 


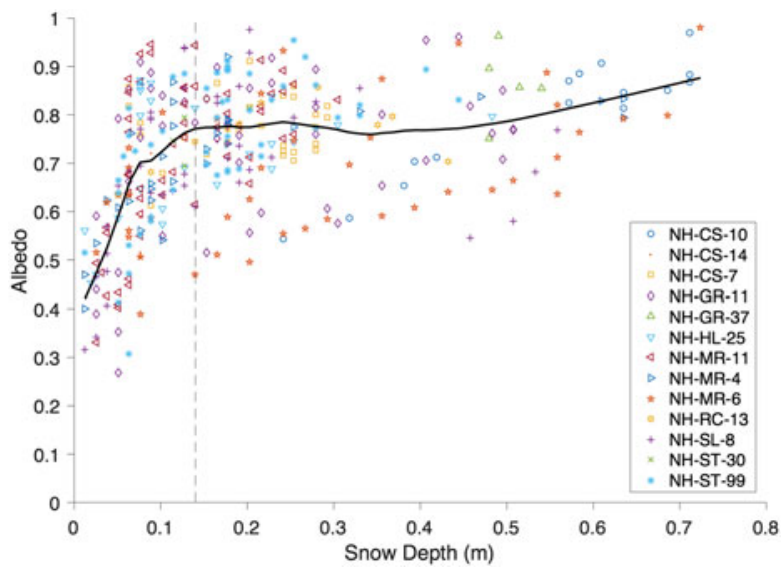

Fig. 4. Snow albedo versus snow depth using data from all decay events from all four winter seasons (2011-15). Station IDs are listed in Table 3. The black line is a LOWESS (locally weighted regression scatterplot smoothing) curve which enables the visibility of trends otherwise obscured by data scatter and outliers. Albedo values are interpreted to plateau beginning at $\sim 0.14 \mathrm{~m}$ snow depth (identified by the dashed vertical line).

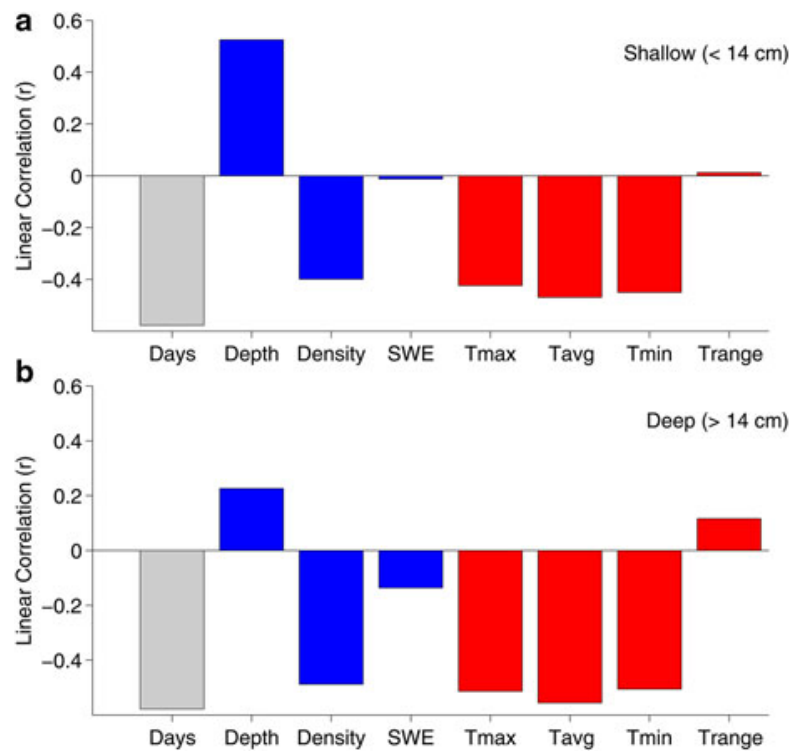

Fig. 5. Linear correlations ( $r$ ) between observed albedo and time (days), snowpack and weather variables during times of albedo decay for calibration dataset; (a) snowpacks SD $<0.14 \mathrm{~m}$ and (b) snowpacks SD $>0.14 \mathrm{~cm}$ displayed. Gray bars represent the time category and includes the snow age variable; blue bars represent the snowpack category and include snow depth, snow density and snow water equivalent (SWE) variables; and red bars represent meteorological parameters which include minimum, average, and maximum daily temperature and daily temperature range.

sensitivity runs. Given the absence of significant correlation between calibration and evaluation dataset selection and model performance, we report the details from the first of the ten calibration and evaluation datasets as being sufficiently representative of the modeling analysis results. The regression equation for shallow snowpacks $(\mathrm{SD}<0.14 \mathrm{~m})$ is expressed as:

$$
\begin{aligned}
\alpha_{\text {shallow }}= & 0.74-3.9 \mathrm{e}^{-2} \tau-1.3 \mathrm{e}^{-2} \bar{T}+4.8 \mathrm{e}^{-3}[\mathrm{SD}] \\
& +3.5 \mathrm{e}^{-4} \tau \bar{T}[\mathrm{SD}]
\end{aligned}
$$

where $\alpha_{\text {shallow }}$ is the predicted albedo value. The regression equation for surface albedo $\left(\alpha_{\text {deep }}\right)$ in deep snowpacks $(\mathrm{SD}>0.14 \mathrm{~m})$ is expressed as:

$$
\alpha_{\text {deep }}=0.91-2.3 \mathrm{e}^{-2} \tau-4.7 \mathrm{e}^{-3} \bar{T}-0.28 \rho+3.4 \mathrm{e}^{-4} \tau \bar{\tau} \rho
$$

The multiple linear regression models are first evaluated on their ability to estimate measured albedo values in the same calibration dataset from which Eqns (2) and (3) were constructed. Modeled albedo from the shallow snowpacks regression show a strong linear correlation with observed albedo, with an $r$ value of 0.75 , RMSE of 0.10 , and slope (calculated using a least-squares fit) of 0.56 (Fig. 6a). The model estimates values of albedo ranging from 0.35 to 0.94 . Modeled albedo values for deep snowpacks (SD > $0.14 \mathrm{~m})$ also show a strong linear relationship $(r=0.72$;
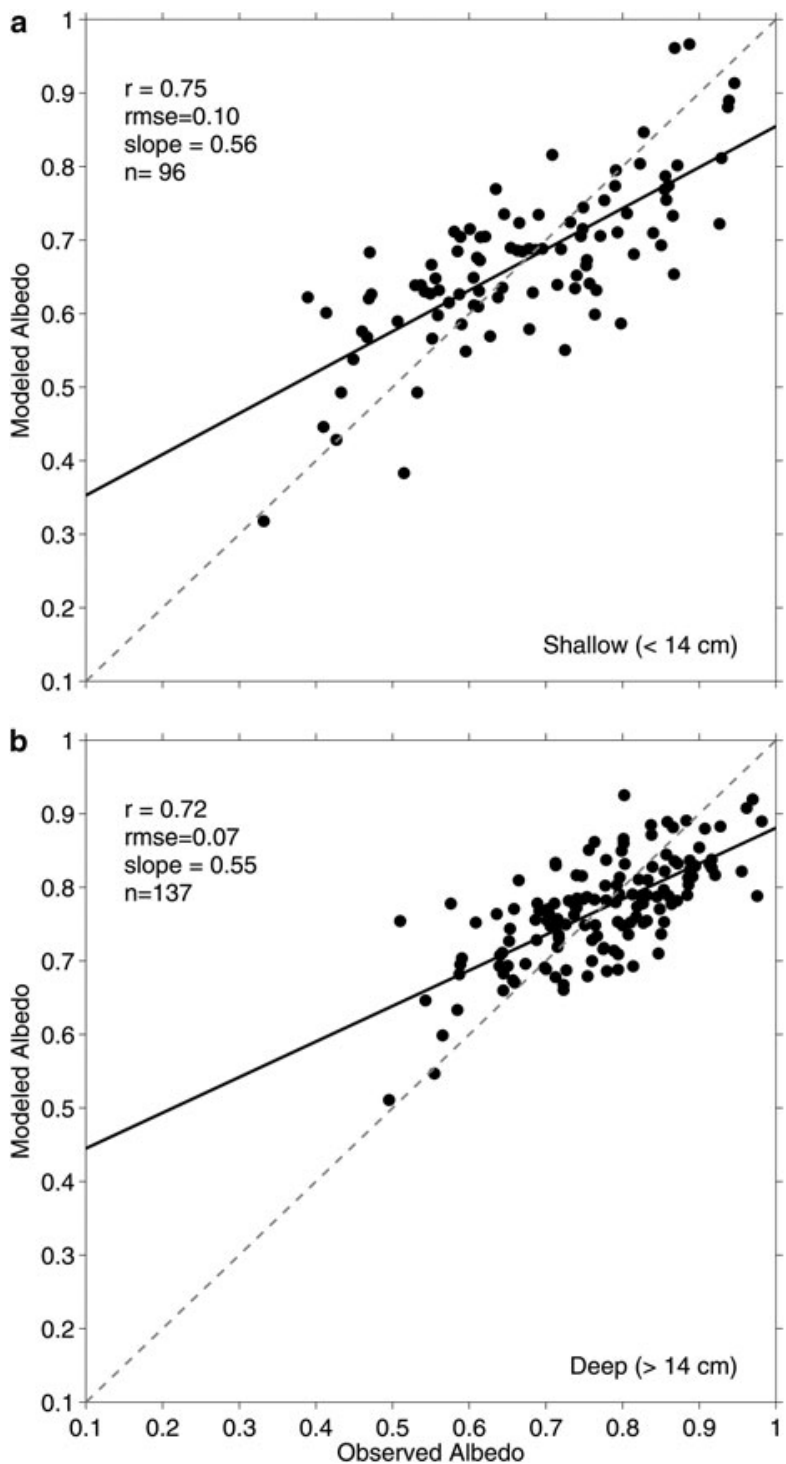

Fig. 6. Albedo values modeled from multiple linear regression using snow age, air temperature and snow properties (snow depth for shallow snowpacks, snow density for deep snowpacks) compared with calibration data for (a) shallow and (b) deep snowpacks. Model skill is assessed using linear correlation (r), RMSE, and slope $(\mathrm{m})$ for both shallow and deep snow covers. $N$ value denotes number of individual measurements on plot. The solid black line represents the least-squares regression line; the dashed grey line is the $1: 1$ line. 
RMS $=0.10$, and a slope of 0.55 ) over a wide range of albedo (Fig. 6b).

The multiple linear regression models were then tested against the evaluation dataset to determine their ability to estimate albedo decay over time. Snow age, snowpack property (SD for shallow snowpacks; $\rho$ for deep snowpacks), and $T$ for each decay interval in the evaluation dataset were input into the models to estimate albedo, and the results compared with measured values (Fig. 7). The shallow snow model predicts 111 albedo values ranging from 0.40 to 0.94 with an $r$ value of 0.70 and an RMSE of 0.10 (Fig. 7a). Compared with the $1: 1$ reference line, the scatter of data trend towards overestimation of low albedo values and under-estimation of high values, also signified by the slope value of 0.57 (similar to results using the calibration dataset in Fig. 6). The deep snow model predicts 116 albedo values from 0.52 to 0.96 with an $r$ value of 0.74 , an RMSE of 0.07 and a slope of
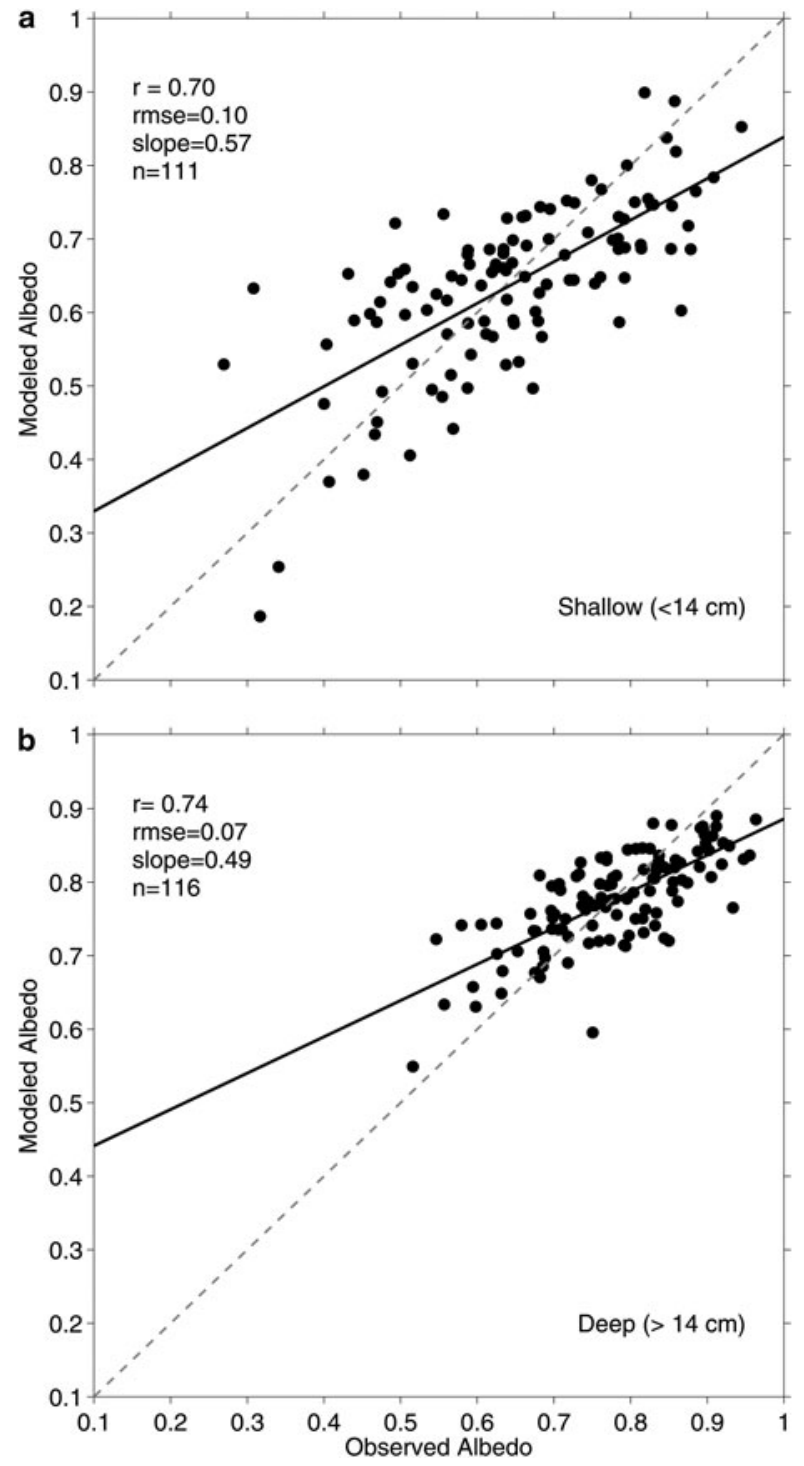

Fig. 7. Albedo values modeled from multiple linear regression using snow age, air temperature and snow properties (snow depth for shallow snowpacks, snow density for deep snowpacks) compared to evaluation data for (a) shallow and (b) deep snowpacks. Model skill is assessed using linear correlation (r), RMSE and slope $(\mathrm{m})$ for both shallow and deep snow covers. $\mathrm{N}$ value denotes number of individual measurements on plot. The solid black line represents the least-squares regression line; the dashed grey line is the 1:1 line.
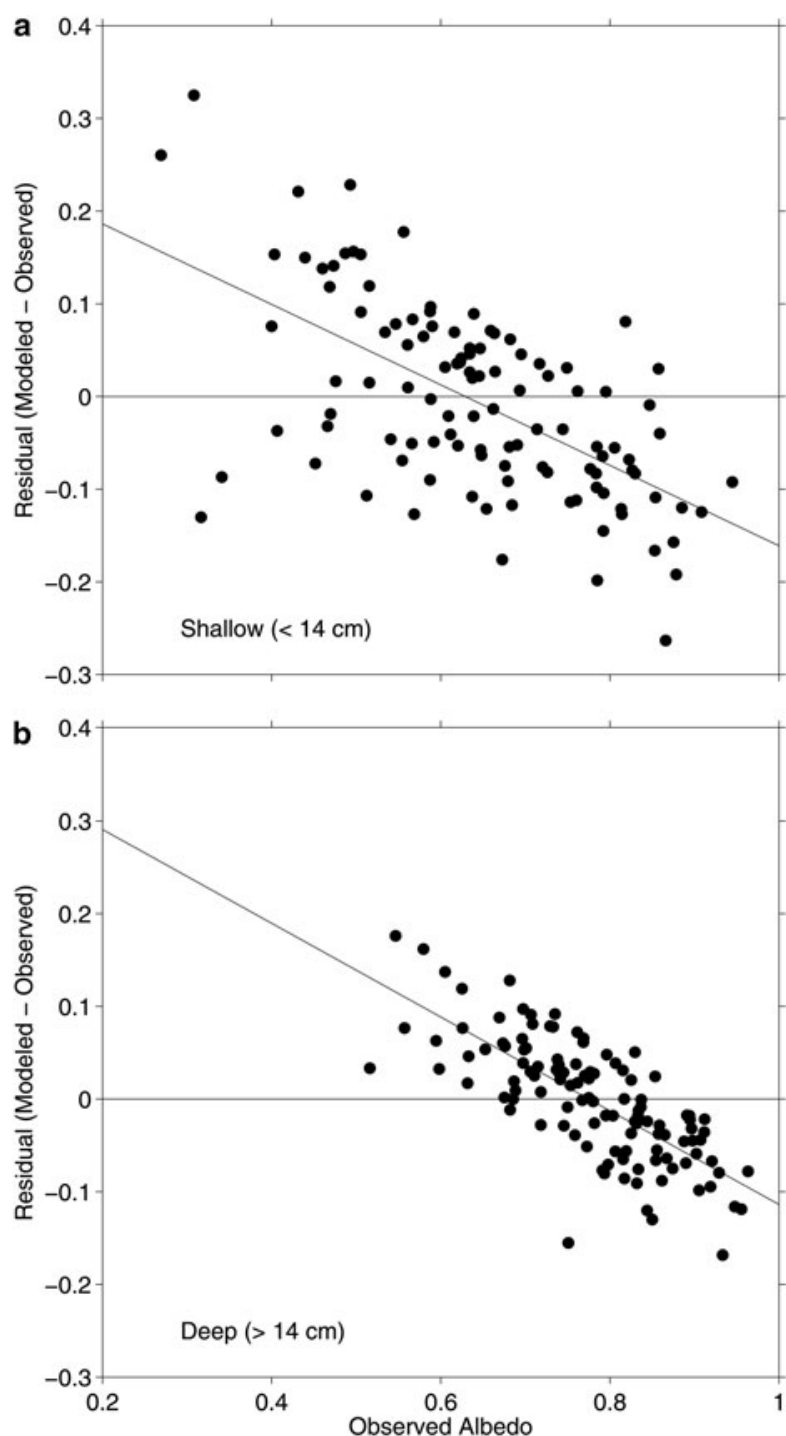

Fig. 8. Residuals (modeled minus observed albedo) plotted against albedo for (a) shallow and (b) deep snowpacks. Both shallow and deep snowpack models over-estimate low albedo and underestimate high albedo. The solid black sloping line represents the least-squares regression line.

0.49 (Fig. 7b). In comparison with the 1:1 reference line, low albedo values are again overestimated while high values are generally underestimated.

Model bias is estimated by calculating the residuals (modeled - observed). The residuals of the multiple linear regression models are plotted against surface albedo and exhibit a clear negative trend for both shallow and deep snowpacks (Fig. 8). In shallow snow, the regression model generally over-estimates albedo $<0.63$, and under-estimates albedo $>0.63$ (Fig. 8a). Despite this bias, $70 \%$ (78 of 111) of modeled albedo values are estimated to within 0.1 of measured albedo while $96 \%$ of modeled values are within 0.2 . In deep snow, albedo is generally over-estimated below 0.78 and under-estimated above 0.78 (Fig. 8b). Ninety percent (104 of 116) of modeled albedo values in deep snowpacks are within 0.1 of measured values, and all are within 0.2 .

\section{DISCUSSION}

The CoCoRaHS-Albedo data exhibit characteristic albedo reduction with increasing snowpack age, consistent with other mid-latitude albedo observations (Pedersen and 
Winther, 2005; Chen and others, 2014; Malik and others, 2014; Adolph and others, 2016) as well as theoretical understanding of albedo evolution (Warren and Wiscombe, 1980; Flanner and Zender, 2006). The results show that large amount of data collected by volunteer observers in the CoCoRaHS-Albedo network are useful for investigating the behavior of surface albedo in seasonal snowpacks.

Trends in surface snow albedo decay over time are analyzed separately in optically deep and optically shallow snowpacks. The surface albedo of optically shallow snow is influenced by the substrate albedo in addition to snow properties, whereas the albedo of optically deep snow depends solely on optical snow parameters. The snow depth marking the transition between optically shallow and optically deep snow is a function of wavelength (Wiscombe and Warren, 1980) and varies considerably depending on snow grain size and density in multilayer radiative transfer models (Zhou and others, 2003). For seasonal snowpacks across New Hampshire over four winter seasons, analysis of hundreds of snow albedo measurements at dozens of sites (Table 3) indicates that the optical snow depth threshold occurs at $\sim 0.14 \mathrm{~m}$ snow depth (Fig. 4). This depth of $0.14 \mathrm{~m}$ is near the upper end of the range of 0.075 to $0.15 \mathrm{~m}$ identified by Baker and others (1991) over surface types varying from bare soil to alfalfa, and slightly more than the value of $0.10 \mathrm{~m}$, which is generally considered an optical threshold depth in surface energy-balance studies (Winther, 1993; Pedersen and Winther, 2005; Perovich, 2007; Mote, 2008; Tanikawa and others, 2009; Aoki and others, 2011).

Optically shallow snowpacks $(\mathrm{SD}<0.14 \mathrm{~m})$ in New Hampshire occur predominantly at the beginning and end of the snow season and occasionally during mid-winter thaws. The albedo decay process of optically shallow snowpacks is more complex compared with deeper snowpacks due to the additional influence of underlying terrain, and accurately parameterizing albedo evolution in shallow snow presents a challenge (Slater and others, 1998). Both shallow and deep snowpacks are subject to surface albedo degradation via snow metamorphism and particulate accumulation. However, albedo reduction of thin snow cover accelerates when solar radiation penetrates through the snow pack and the lower albedo of the underlying substrate increases absorption of solar radiation. As snow cover decreases, surface albedo approaches that of the substrate until snow cover disappears altogether (Gray and Landine, 1987). Additionally, the presence of adjacent bare ground further accelerates snow melt where snow remains. In the CoCoRaHS-Albedo dataset, correlation between snow depth and surface albedo for shallow snowpacks implies snow depth represents some of the complex influences on snow surface albedo brought about by visible ground beneath the snowpack and adjacent bare ground. In addition, the large scatter and lower albedo values (albedo $<0.45$ ) in the residuals plot for shallow snowpacks (Fig. 8a) are indicative of the influence of the underlying substrate.

In optically deep snowpacks (SD $>0.14 \mathrm{~m}$ ), both theoretical and empirical studies show that snow surface albedo declines principally in response to complex metamorphosis within the snowpack that increase optical grain size and concentration of impurities (Warren and Wiscombe, 1980, Wiscombe and Warren, 1980; Warren, 1982; Aoki and others, 2000, 2003; Cabanes and others, 2002; Flanner and Zender, 2006; Domine and others, 2008). At air temperatures higher than $0{ }^{\circ} \mathrm{C}$, the presence of liquid water within the snow matrix enhances grain growth, further reducing albedo (Colbeck, 1982; Flanner and Zender, 2006) and increasing snow density. Surface albedo can also be reduced via accumulation of particles, including black carbon (BC), on the snow surface (Warren and Wiscombe, 1980; Flanner and others, 2007; Doherty and others, 2013). However, recent measurement and analysis of albedo and BC at three open sites across New Hampshire over three winter seasons have shown that BC has a minimal effect on albedo compared with optical grain size of the surface snow (Adolph and others, 2016).

While acknowledging these complexities, we have attempted to develop simple linear models to estimate albedo decay in snowpacks based solely on snow age, snowpack properties (depth or density), and $2 \mathrm{~m}$ air temperature; all of which are assumed to be proxy variables for changes in microphysical snowpack properties, such as grain growth and impurity loading. Our approach incorporates easily replicable, low cost data collection methods and analysis. Calibration and evaluation of multiple linear regression Eqns (2) and (3) in the context of quantifying snow albedo decay behavior confirm strong relationships among snow surface albedo values, snowpack age and $2 \mathrm{~m}$ air temperature, which are commonly available in climate model routines. Snow age and $2 \mathrm{~m}$ air temperature are found to be important determinants of surface albedo for both shallow and deep snow covers; however, addition of simple snowpack measures enhances the estimation of albedo in both snow cover types. For snowpacks with $\mathrm{SD}<0.14 \mathrm{~m}$ deep, albedo is more strongly correlated with snow depth than snow density, indicative of the contribution of underlying terrain to snow surface albedo as well as the influence of adjacent snow cover fraction. For snowpacks with SD > $0.14 \mathrm{~m}$ in depth, albedo is more strongly correlated with snow density than snow depth, likely owing to its surrogate connection with snow grain evolution processes and liquid water content

In Table 5 we report the skill of our deep snowpack model in comparison with similar albedo schemes developed by Verseghy (1991); Douville and others (1995) and Adolph and others (2016). It is acknowledged that these models calculate albedo solely as functions of snow age and air temperature. The intent of our comparison is not to determine the best parameterization but rather to understand the strengths and deficiencies of simple albedo modeling approaches. Verseghy (1991) and Douville and others (1995) both employ exponential prognostic equations for albedo decay dependent on snow age and air temperature. Adolph and others (2016) present a linear regression model using snow age and mean air temperature to compute albedo decay of snow at a single $\mathrm{NH}$ site over three of the four winter seasons studied here. Although the three other

Table 5. Summary statistics for albedo decay models tested on CoCoRAHS-Albedo evaluation data for optically thick snowpacks $(\mathrm{SD}>0.14 \mathrm{~m})$

\begin{tabular}{llcc}
\hline Study & $r$ & RMSE & Slope \\
\hline Verseghy (1991) & 0.55 & 0.09 & 0.44 \\
Douville and others (1995) & 0.56 & 0.09 & 0.46 \\
Adolph and others (2016) & 0.56 & 0.09 & 0.28 \\
This paper & 0.74 & 0.07 & 0.49
\end{tabular}


models use $0.10 \mathrm{~m}$ as an optical threshold and thus were developed for use on snowpacks exceeding this depth, we tested all models using snowpacks deeper than $0.14 \mathrm{~m}$ since we observed this depth to be the optical threshold for snowpacks in $\mathrm{NH}$.

The models from the literature exhibit similar skill to one another when tested against 116 daily deep snowpack CoCoRaHS-Albedo observations, with linear correlation factors of $0.55-0.56$ and slopes of $0.28-0.46$. The model presented in this paper has both a higher $r$ value $(0.74)$ and slope (0.49) than the other three, but this is unsurprising considering it was developed using CoCoRaHS-Albedo data. All four models accurately compute albedo values from 0.7 to 0.8 but diminish in capability outside of this range, regardless of whether decay is represented as a linear or exponential process. The three models from the literature struggle with under-estimation of high albedo values and over-estimation of low albedo values to a greater degree than our model does, as illustrated by slope values all $<0.5$ (Table 5). A portion of this variability may be explained by the fresh snow reset values of 0.84 (Douville and others, 1995) and 0.85 (Verseghy, 1991), which represent albedo maxima for their respective models; these albedo values are less than a substantial number $(24 \%)$ of measured albedo values in the CoCoRaHS-Albedo deep snow evaluation dataset.

Despite the encouraging performance of the two multiple linear regression models developed in this study, systematic biases highlight an important non-linearity in albedo decay and snowpack evolution. Modeled albedo values are reasonably accurate within the range of $0.6-0.9$, but exhibit a tendency to over-estimate lower albedo values and under-estimate higher albedo values. We hypothesize that this characteristic of all the linear models is due to the dominance of slow metamorphic evolution of snow grains through most of the winter season. Fresh snow, with highest albedo, experiences more rapid changes as vapor transfer leads to rounding of microstructures and decrease in the snow specific surface area (Cabanes and others, 2002; Domine and others, 2008). Later in the season and during mid-winter melt events, the presence of liquid water in the snowpack results in accelerated metamorphism and grain growth (Colbeck, 1982). Simple models assuming constant rates of grain evolution are unable to capture these important intervals of faster evolution.

\section{CONCLUSIONS}

Quantifying the variability of snow albedo via direct observations is critical for accurate representation of surface energy balance in numerical models. Over the course of four consecutive winter seasons CoCoRaHS-Albedo volunteers collected 3249 daily albedo and snowpack measurements from sites across New Hampshire, amassing an observational dataset that, to our knowledge, represents the densest array of ground-based albedo measurements in a temperate seasonal snowpack. Analysis of the spatially robust dataset demonstrates the optical snow depth threshold value to be $\sim 0.14$ $\mathrm{m}$ snow depth.

Simple multiple linear regression models using snowpack age, snow depth or snow density and $2 \mathrm{~m}$ air temperature provide reasonable estimates of surface snow albedo during times of albedo decay at sites across New Hampshire for both shallow (SD $<0.14 \mathrm{~m}$ ) and deep (SD $>$ $0.14 \mathrm{~m}$ ) snowpacks. Despite strong correlation with observed values, estimated albedo exhibit a tendency to overestimate low albedo values and underestimate high albedo, suggesting our set of predictor variables may best model albedo reduction over a limited range of linear response (0.6-0.9). We hypothesize that more rapid changes in albedo in fresh snow (albedo $>0.9$ ) are the result of vapor transfer causing rounding of microstructures and a decrease in the snow specific surface area, while during melt-events the presence of liquid water in the snowpack (albedo <0.6) accelerates metamorphism and rapid grain growth results.

The CoCoRaHS-Albedo network represents an albedo measurement campaign that relies upon volunteer observers to provide a dense array of snow albedo observation at dozens of sites across New Hampshire. Weather-enthusiasts, primary and secondary school educators, students and university researchers alike contributed scientifically-useful observational data from dispersed locations, successfully providing data suitable for climate model validation (Burakowski and others, 2013) and empirical albedo decay modeling. Although volunteer observers ultimately provided the bulk of suitable measurements, engagement with primary and secondary school educators has fostered many local scientific outreach opportunities, including a high school snow sampling lesson plan that meets Next Generation Science Standards (Hanson and Burakowski, 2015). We conclude that the CoCoRaHS-Albedo volunteer observer network provides useful snow albedo, depth and density measurements and serves as an effective model for future measurement campaigns.

\section{ACKNOWLEDGEMENTS}

We thank all of the volunteer observers in the CoCoRaHSAlbedo Network for their contributions to this study. This work was supported by the New Hampshire EPSCoR Program with funding provided by the National Science Foundation's Research Infrastructure Improvement Award EPS 1101245. Data collected throughout the NH EPSCoR Track 1 project, including data leading to relevant conclusions in this work, can be found on the Data Discovery Center at http://ddc-albedo.sr.unh.edu. We also appreciate the reviewer comments and helpful critiques on earlier drafts of this manuscript.

\section{REFERENCES}

Adolph AC and 5 others (2016) Dominance of grain size impacts on seasonal snow albedo at open sites in New Hampshire. J. Geophys. Res., 122, 121-139 (doi: 10.1002/2016JD025362)

Aoki T and 5 others (2000) Effects of snow physical parameters on spectral albedo and bidirectional reflectance of snow surface. J. Geophys. Res., 105, 10219-10236.

Aoki T, Hachikubo A and Hori M (2003) Effects of snow physical parameters on shortwave broadband albedos. J. Geophys. Res., 108(D19), 4616 (doi: 10.1029/2003JD003506)

Aoki T and 5 others (2011) Physically based snow albedo model for calculating broadband albedos and the solar heating profile in snowpack for general circulation models. J. Geophys. Res., 116, D11114 (doi: 10.1029/2010JD015507)

Augustine JA, DeLuisi JJ and Long CN (2000) SURFRAD - A national surface radiation budget network for atmospheric research. Bull. Amer. Meteor. Soc., 81, 2341-2357

Baker DG, Skaggs RH and Ruschy DL (1991) Snow depth required to mask the underlying surface. J. App. Meteorology, 30(3), 387-392

Brown RD and Robinson DA (2011) Hemisphere spring snow cover variability and change over 1922-2010 including an assessment 
of uncertainty. Cryosphere, 5, 219-229 (doi: 10.5194/tc-5-2192011)

Burakowski EA, Wake CP, Braswell B and Brown DP (2008) Trends in wintertime climate in the northeastern United States: 1965-2005. J. Geophys. Res., 113, D20114 (doi: 10.1029/2008JD009870)

Burakowski EA, Wake CP, Dibb JE and Stampone M (2013). Putting the capital ' $A$ ' in CoCoRAHS: an experimental programme to measure albedo using the community collaborative rain, hail \& snow (CoCoRaHS) network. Hydro Proc., 27(21), 3024-3034

Burakowski EA and 5 others (2016) Evaluating the climate effects of reforestation in New England, USA, using a weather research and forecasting (WRF) model multi-physics ensemble. J. Climate, 29, 5141-5156 (doi: 10.1175/JCLI-D-15-0286.1)

Cabanes A, Legagneux L and Domine F (2002) Evolution of the specific surface area and of crystal morphology of Arctic fresh snow during the ALERT 2000 campaign. Atmos. Environ., 36, 2767-2777

Chen A, Weiping L, Weijing L and Xin L (2014) An observational study of snow aging and the seasonal variation of snow albedo by using data from Col de Porte, France. Chin. Sci. Bull., 59 (34), 4881-4889

Cifelli $R$ and 6 others (2005) The community collaborative rain, hail, and snow network: informal education for scientists and citizens. Bull. Am. Meteorol. Soc., 86(8), 1069-1077 (doi: 10.1175/ BAMS-86-8-1069)

Colbeck SC (1982) An overview of seasonal snow metamorphism. Rev. Geophys. Space Phys., 20, 45-61.

DeGaetano A, Belcher B and Noon W (2015) Temporal and spatial interpolation of the standardized precipitation index for computational efficiency in the dynamic drought index tool. J. Appl. Meteor. Climatol., 54, 795-810 (doi: 10.1175/JAMC-D-14-0088.1)

Doherty SJ and 5 others (2013) Observed vertical redistribution of black carbon and other insoluble light-absorbing particles in melting snow. J. Geophys. Res. Atmos., 118, 5553-5569 (doi: 10.1002/jgrd.50235)

Domine $\mathrm{F}$ and 7 others (2008) Snow physics as relevant to snow photochemistry. Atmos. Chem. Phys., 8, 171-208

Douville H, Royer JF and Mahfouf JF (1995) A new snow parameterization for the meteo-France climate model part I: validation in stand-alone experiments. Clim. Dyn., 12, 21-35

Estilow TW, Young AH and Robinson DA (2015) A long-term Northern hemisphere snow cover extent data record for climate studies and monitoring. Earth Syst. Sci. Data, 7, 137-142 (doi: 10.5194/essd-7-137-2015)

Flanner MG and Zender CS (2006) Linking snowpack microphysics and albedo evolution. J. Geophys. Res., 111, D12208 (doi: 10.1029/2005JD006834)

Flanner MG, Zender CS, Randerson JT and Rasch PJ (2007) Presentday climate forcing and response from black carbon in snow. J. Geophys. Res., 112, D11202 (doi: 10.1029/2006JD008003)

Flanner MG, Shell KM, Barlage M, Perovich DK and Tschudi MA (2011) Radiative forcing and albedo feedback from the Northern hemisphere cryosphere between 1979-2008. Nat. Geosci., 4, 151-155 (doi: 10/1038/ngeo1062)

Fletcher CG, Zhao H, Kushner PJ and Fernandes R (2012) Using models and satellite observations to evaluation the strength of snow albedo feedback. J. Geophys. Res., 117, D11117 (doi: 10.1029/2012JD017724)

Gardner AS and Sharp M (2010) A review of snow and ice albedo and the development of a new physically based broadband albedo parameterization. J. Geophys Res., 115 (doi: 10.1029/ 2009JF001444)

Gray DM and Landine PG (1987) Albedo model for shallow prairie snow covers. Can. J. Earth Sci., 24, 1760-1768

Groisman PY, Karl TR and Knight RW (1994) Observed impact of snow cover on the heat balance and the rise of continental spring temperatures. Science, 263, 198-200

Hopper LJ Jr and Schumacher C (2012) Modeled and Observed Variations in Storm Divergence and Stratiform Rain Production in Southeastern Texas. J. Atmos. Sci. 69, 1159-1181 (dol: 10.1175/ JAS-D-11-092.1)
Hanson E and Burakowski EA (2015) Sampling in the snow: winter field experiences provide relevant, real world connections between scientific practice and disciplinary core ideas. Sci. Teacher, 82, 36-41

Lemke P and 10 others (2007) Observations: changes in snow, Ice and frozen ground. In Solomon S, Qin D, Manning M, Chen Z, Marquis $\mathrm{M}$, Averyt KB, Tignor $\mathrm{M}$ and Miller HL, eds. Climate change 2007: the physical science basis. Contribution of working group I to the fourth assessment report of the intergovernmental panel on climate change, 339-383 Cambridge University Press, Cambridge, United Kingdom and New York, NY, USA.

Loew A and 5 others (2016) A database of global reference sites to support validation of satellite surface albedo datasets (SAVS 1.0). Earth Syst. Sci. Data, 8, 425-438 (doi: 10.5194/essd-8-425-2016)

Malik MJ, van der Velde R, Vekerdy Z and Su Z (2014) Improving modeled snow albedo estimates during the spring melt season. J. Geophys. Res. Atmos., 119, 7311-7331 (doi: 10.1002/ 2013JD021344)

Mote TL (2008) On the role of snow cover in depressing air temperature. J. Appl. Meteor. Climatol., 47, 2008-2022 (doi:10.1175/ 2007JAMC1823.1)

Pedersen CA and Winther JG (2005) Intercomparison and validation of snow albedo parameterization schemes in climate models. Clim. Dyn., 25, 351-362 (doi: 10.1007/s00382-0050037-0)

Perovich DK (2007) Light reflection and transmission by a temperate snow cover. J. Glaciol., 53(181), 201-210

Qu X and Hall A (2006) Assessing snow albedo feedback in simulated climate change. J. Climate, 19, 2617-2630

Robock A (1980) The seasonal cycle of snow cover, sea ice and surface albedo. Mon. Wea. Rev., 108, 267-285

Robock A and 7 others (2000) The global soil moisture data bank. Bull. Amer. Met. Soc., 81, 1281-1299

Schwartz CS (2014) Reproducing the September 2013 record-breaking rainfall over the Colorado front range with high-resolution WRF forecasts. Wea. Forecasting, 29(2), 393-402

Sharma S, Isik S, Srivastava P and Kalin L (2013) Deriving spatiallydistributed precipitation data using the artificial neural network and multi-linear regression models. J. Hydrologic Eng., 18, 194-205

Shewchuk SR (1997) Surface mesonet for BOREAS. J. Geophys. Res., 102(D24), 29077-29082 (doi: 10.1029/96JD03875)

Slater AG, Pitman AJ and Desborough CE (1998) The validation of a snow parameterization designed for use in general circulation models. Int. J. Climatol., 18, 595-617

Smith BK, Smith JA, Baeck ML and Miller AJ (2015) Exploring storage and runoff generation processes for urban flooding through a physically based watershed model. Water Resour. Res., 51, 1552-1569 (doi: 10.1002/2014WR016085)

Steffen K, Bo JE and Abdalati W (1996) Greenland climate network: GCNet, US Army Cold Regions Reattach and Engineering (CRREL). CRREL Special Report, 98-103

Sugg JW, Perry LB, Hall DK, Riggs GA and Badurek CA (2014) Satellite perspectives on the spatial patterns of new snowfall in the southern Appalachian mountains. Hydrol. Process., 28, 4602-4613 (doi: 10.1002/hyp.10196)

Tanikawa T and 5 others (2009) Effect of snow impurities and vertical profile on snow albedo and reflectance. EOS Trans. AGU, 90 (52), Fall Meet. Suppl., Abstract C33C-0519

van As D, Fausto RS, Colgan WT and Box JE and PROMICE project team (2013) Darkening of the Greenland ice sheet due to the melt-albedo feedback observed at PROMICE weather stations. Geol. Surv. Denmark Greenland Bull., 28, 69-72

van den Broeke M, van As DS, Reijmer C and van de Wal R (2004) Assessing and improving the quality of unattended radiation observations in Antarctica. J. Atmos. Oceanic Technol., 21, 1417-1431 (doi: 10.1175/1520-0426)

Verseghy DL (1991) CLASS—a Canadian land surface scheme for GCMs. I. Soil model. Int. J. Climatol., 11(2), 111-133 
Warren SG (1982) Optical properties of snow. Rev. of Geophys. Space Phys., 20(1), 67-89

Warren SG and Wiscombe WJ (1980) A model for the spectral albedo of snow. II: snow containing atmospheric aerosols. J. Atmos. Sci., 37(12), 2734-2745

Winther JG (1993) Short- and long-term variability of snow albedo. Nord. Hydrol., 24, 199-212
Wiscombe WJ and Warren SG (1980) A model for the spectral albedo of snow. I: pure snow. J. Atmos. Sci., 37(12), 2712-2733

Zhou X, Li X and Stamnes K (2003) Effects of vertical inhomogeneity on snow spectral albedo and its implication for optical remote sensing of snow. J. Geophys. Res., 108(D23), 4738 (doi: 10.1029/2003JD003859)

MS received 9 December 2016 and accepted in revised form 17 August 2017 